\title{
Post-Match Changes in Muscle Damage Markers among U-21 Soccer Players
}

\author{
Nebojsa Trajkovic ${ }^{1}$, Goran Sporis ${ }^{2}$, Tomislav Vlahovic ${ }^{2}$, Dejan Madic ${ }^{1}$, Marko Gusic ${ }^{1}$
}

Affiliations: 'University of Novi Sad, Faculty of Sport and Physical Education, Novi Sad, Serbia, ${ }^{2}$ University of Zagreb, Faculty of Kinesiology, Zagreb, Croatia

Correspondence: N. Trajkovic, University of Novi Sad, Faculty for Sport and Physical Education, Lovcenska 16, 21000 Novi Sad, Serbia. E-mail: nele_trajce@yahoo.com

ABSTRACT This study aimed to investigate the effect of official soccer matches on selected markers of muscle damage in U-21 soccer players. A group of 19 trained, healthy male soccer players from the junior category took part in this study. Blood samples were assessed pre-match and immediately after a match in response to a competitive $(2 \times 45 \mathrm{~min})$ soccer match. Analysis was performed for muscle damage and inflammatory markers. Significant differences between two measures (before and after soccer match) exist in Aspartate-aminotransferase (AST), Lactate dehydrogenase (LDH), and Myoglobin. Plasma $\mathrm{K}^{+}$significantly decreased after the match $(\mathrm{p}<0.05)$, whereas plasma $\mathrm{Na}^{+}$decreased slightly. This study showed that most selected markers of muscle damage were influenced by a soccer match. However, results remain inconsistent because of the influence of the type, duration, and intensity of exercise. Moreover, some markers show great variability among individuals.

KEY WORDS football, fatigue, junior players, competitive match

0

$@ M J S S M o n t e n e g r o$

MUSCLE DAMAGE MARKERS IN SOCCER

http://mjssm.me/?sekcija=article\&artid=163

\section{Introduction}

Regular physical activity can have significant health benefits. However, some activities might not be healthy, due to dehydration, substrate depletion, muscle damage, inflammation, and the increased production of free radicals. Free radicals, which are particularly produced as a result of physical exercise (Cooper, Vollaard, Choueiri, \& Wilson, 2002), are involved in the process of muscle fatigue, many diseases, and aging (Finaud, Lac, \& Filaire, 2006). Although there is no definitive conclusion on fatigue, it is assumed that two main origins are involved in this process. The first is the central fatigue hypothesis, in which the central nervous system blocks continued extraordinary effort, perhaps as protection from injury (Taylor, Allen, Butler, \& Gandevia, 2000). The second is the peripheral fatigue, in which the muscle's homeostasis has been perturbed, either through tissue damage, or some other way, to the point that the muscle is incapable of responding as effectively as it does when rested (MacIntosh \& Rassier, 2002).

Nybo et al. (2013) suggested that muscle pain, reduced power, increased creatine kinase, Myoglobin, aspartate aminotransferase and lactate dehydogenase levels are the most significant indicators of muscle damage. Two studies have used very high intensity or volume of exercise to provoke muscle damage (Byrne \& Eston, 2002; Davies, Rowlands, \& Eston, 2009). However, match activity in soccer is influenced by several factors. The style of play can influence the physiological demands on players. The national teams of Ireland and Norway use the "direct method of play", maintaining the game at a high pace (Reilly, 1997). Thus, the findings of a recent study (Gregson, Drust, Atkinson, \& Salvo, 2010) indicate that match-to-match variability in performance characteristics of elite soccer players is high. Moreover, many factors within the body can influence muscle damage, such as inflammation (Stoner et al., 2013), nutrition (Muñoz \& Costa, 2013), intake of supplements (Goldfarb, 1999; Goldfarb, Garten, Cho, Chee, \& Chambers, 2011). A significant increase in muscle damage markers (Andersson, Ekblom, \& Krustrup, 2008; Ascensão et al., 2008; Ispirlidis et al., 2008; Magalhães et al., 2010) has been described immediately after "friendly" soccer matches and throughout the post-match recovery. Ascensão et al. (2008) and more recently Fatouros et al. (2010) found noticeable muscle damage up to 72 hours post-exercise, following a soccer match. 
There have been numerous studies on muscle damage after competitive matches in multiple sprint sports involving body contact, such as soccer, rugby, and field hockey. However, only a few studies have evaluated muscle damage markers immediately after the official soccer match. Therefore, this paper aimed to estimate the markers of muscle damage in U-21 players, before and immediately after an official soccer match.

\section{Methods}

Participants

A group of 19 trained, healthy male soccer players from the junior category of a Croatian soccer association took part in this study. The players were informed about the experimental procedures and possible discomforts associated with the study, and written informed consent was obtained. The study was approved by the Ethics Committee of the Faculty of Kinesiology, University of Zagreb and according to the Helsinki Declaration. The participants were aware that they could withdraw from the study at any time. The participant's characteristics were in average: age $20.26 \pm 0.65$ years, mean \pm SD: body mass: $71.3 \pm 5.9$; body height: 1.77 \pm 0.07 and maximal oxygen uptake (VO2max) $64.95 \pm 3.99 \mathrm{ml} \cdot \mathrm{kg}-1 \cdot \mathrm{min}-1$. Selection criteria included: (1) participation at professional (top three division leagues) level of soccer competition for at least 5 years, (2) all players participated in at least $75 \%$ of the training sessions per week and played at least 16 matches during season, (3) no consumption of exogenous anabolic-androgenic steroids or other drugs that might have affected their physical performance or hormonal balance during the study (for at least 6 months) (4) no recent history of febrile illness, muscle lesions, lower limb trauma, or metabolic diseases. Soccer players were instructed not to change their normal eating habits during the entire period of data collection. Nutritional supplements were not included in their diets. In addition, players were instructed to refrain from drinking beverages containing caffeine or alcohol and from consuming food in the $3 \mathrm{~h}$ before testing.

\section{Blood collection and analysis}

Blood samples were assessed pre-match and immediately after the match in response to a competitive $(2 \times 45$ $\mathrm{min}$ ) soccer match. On the day of the game, players arrived at the laboratory after an overnight fast of between 10 and $12 \mathrm{~h}$. A resting blood sample was taken after participants had been standing for at least $15 \mathrm{~min}$, after which participants consumed a light standardized meal and drink and rested for $2 \mathrm{~h}$. The meal consisted of $1.7 \mathrm{~g}$ white bread and $0.3 \mathrm{~g}$ of low-fat spread (both values are per kilogram of body mass) (Thompson et al., 2003). Participants abstained from alcohol and caffeine consumption for at least $24 \mathrm{~h}$ and did not perform any exercise for the $72 \mathrm{~h}$ before testing.

Fasting venous blood samples were withdrawn into heparinized tubes from a cubital vein just before and immediately after the soccer match, then centrifuged at $3000 \mathrm{rpm}$ for $10 \mathrm{~min}$ to separate the plasma. The plasma samples were stored at $-20^{\circ} \mathrm{C}$ until the analysis of muscle damage and inflammatory markers.

Concerning the muscle damage and inflammatory markers, analysis of Myoglobin, Creatine kinase (CK), Lactate dehydrogenase (LDH), Aspartate-aminotransferase (AST), C-reactive protein (CRP) were automatically performed using a Dimension Xpand Plus Analyzer (Siemens, Munich, Germany). Plasma concentrations of $\mathrm{K}+$ and $\mathrm{Na}+$ were determined using commercially available assays on a Dimension Xpand Plus Analyzer (Siemens, Munich, Germany).

\section{Statistical analysis}

All statistical analyses were performed using the STATISTICA v.8.0 software (StatSoft Inc., Tulsa, OK, USA). Descriptive statistics and Kolmogorov-Smirnov (normality of the distribution) tests were calculated for all experimental data before inferential testing. Data were expressed as mean values \pm standard deviation. A sample t-test was used to analyse where the significant variations occurred. Effect size (ES) was classified as follows: $<0.2$ was defined as trivial, $0.2-0.6$ was defined as small, 0.6-1.2 was defined as moderate, 1.2-2.0 was defined as large, $>2.0$ was defined as very large and $>4.0$ was defined as extremely large (Hopkins, Marshall, Batterham, \& Hanin, 2009). Statistical significance was set at $\mathrm{p}<0.05$.

\section{Results}

As can be seen in Table 1, statistically significant differences between two measures (before and after soccer match) exist in AST $(\mathrm{p}<0.05)$. Furthermore, LDH values were significantly higher immediately after the

\begin{tabular}{|c|c|c|c|c|}
\hline & Prematch & Postmatch & \%diff & ES \\
\hline Mioglobin (ng/mL) & $33.29 \pm 14.91$ & $277.77 \pm 131.19^{*}$ & 734.4 & 2.61 \\
\hline CRP (mg/dL) & $0.52 \pm 0.34$ & $0.50 \pm 0.39$ & -3.8 & -0.05 \\
\hline AST (U/L) & $25.58 \pm 11.16$ & $34.21 \pm 14.81^{*}$ & 33.7 & 0.65 \\
\hline CK (IU/L) & $483.53 \pm 910.78$ & $530.89 \pm 442.52$ & 9.8 & 0.06 \\
\hline LDH (U/L) & $195.68 \pm 26.71$ & $273.74 \pm 35.08^{*}$ & 39.9 & 2.50 \\
\hline
\end{tabular}

Note: (CRP) C-reactive protein, (AST) Aspartate-aminotransferase, (CK) Creatine kinase, (LDH) Lactate dehydrogenase, ${ }^{*} p<0.05$ from the corresponding pre-match value. 
match $(\mathrm{p}<0.05)$. No significant changes were observed in plasma CK activity after the match $(\mathrm{p}>0.05)$. This was also the case with CRP levels, for which similar results were obtained following the match ( $\mathrm{p}=0.87)$. Plasma Myoglobin concentrations were significantly higher after the match in comparison to pre-match values $(\mathrm{p}<0.05)$.

Table 2 shows plasma concentrations of $\mathrm{K}^{+}$and $\mathrm{Na}^{+}$measured before and after the matches. Plasma $\mathrm{K}^{+}$was significantly decreased after the match $(\mathrm{p}<0.05)$, whereas plasma $\mathrm{Na}^{+}$gradually decreased.

\begin{tabular}{|c|c|c|c|c|}
\hline & Prematch & Postmatch & \%diff & ES \\
\hline $\mathrm{K}(\mathrm{mmol} / \mathrm{L})$ & $4.56 \pm 0.27$ & $4.29 \pm 0.33^{*}$ & $-5.9 \%$ & -0.89 \\
\hline $\mathrm{Na}(\mathrm{mmol} / \mathrm{L})$ & $140.47 \pm 1.43$ & $137.48 \pm 19.49$ & $-2.1 \%$ & -0.22 \\
\hline
\end{tabular}

Note: K- potassium; Na- sodium: ${ }^{*} \mathrm{p}<0.05$ from the corresponding pre-match value.

\section{Discussion}

The purpose of the present study was to investigate the accuracy of selected markers to reflect changes in fatigue in male U-21 players after an official soccer match. The results of this study showed that significant changes occurred immediately after an official soccer match. We found that plasma LDH, AST and Myoglobin levels increased. In addition, $\mathrm{K}^{+}$levels were significantly different before and after the match.

Previous investigations have reported that a single soccer match educes significant changes in muscle damage markers for as long as $48 \mathrm{~h}$ to $72 \mathrm{~h}$ post-exercise (Ascensão et al., 2008; Ispirlidis et al., 2008; Silva et al., 2013). Published data are inconsistent for many markers of muscle damage depending on the type, duration, and intensity of exercise. For instance, Takahashi et al. (2007) reported that only LDH increased after a rugby match lasting $10 \mathrm{~min}$, while CK, AST, and ALT remained essentially unchanged. In contrast to this, Burger-Mendonca, Bielavsky, and Barbosa (2008) showed that maximal physical exercise leads to significant elevation of muscle damage markers and enzymes.

Lazarim et al. (2009) analysed the changes in CK levels in 128 professional soccer players at different times during the Brazilian national championship. The aforementioned authors identified the upper limit reference value of $950 \mathrm{IU} / \mathrm{L}$ as the decision limit to detect muscle overload. Recently, Hammouda, Chaouachi, Ferchichi, Kallel, and Souissi (2012) showed increased CK and LDH levels after the level-1 Yo-Yo intermittent recovery test in young soccer players. Accordingly, Brancaccio, Lippi, and Maffulli (2010) consider these markers as essentially indicative of muscle damage. In this study, no significant change was observed in CK levels following an official soccer match in junior players. It is possible that due to the high frequency of matches and inadequate recovery soccer players can have consistently elevated CK, which was confirmed in one study (Heisterberg et al., 2013 ). Our data show much higher values compared to the upper reference value (270 $\mathrm{UI} / \mathrm{L}$ ), for the general population (Mougios, 2007). Furthermore, the high variability of the measure of CK activity must also be taken into account (Halson, 2014), which was the case in this study. Research conducted on elite soccer players has also reported large variability in CK levels (Meister, Faude, Ammann, Schnittker, \& Meyer, 2013). Moreover, some athletes show only small increases in CK activity due to a lower permeability of muscle cell membranes (Urhausen \& Kindermann, 2002). Bearing in mind that activities of CK and Myoglobin correlate with a neutrophil response induced by stress (Suzuki et al., 1999), Myoglobin represents a useful marker to monitor the effectiveness of workload on muscle tissue in training (Speranza et al., 2007). After a soccer match, Myoglobin may increase within $30 \mathrm{~min}$ (Ascensão et al., 2008), and remain increased for 72 hours, which is probably the result of low-grade inflammation (Neubauer, König, \& Wagner, 2008). The present findings indicate that Myoglobin levels increased significantly after an official soccer match in junior professional players, which is in line with other studies.

CRP is a well-characterized biomarker of chronic inflammation. However, it is significantly influenced by BMI, gender, age, and smoking status (Shanely et al., 2013). Accordingly, a very small decrease in C-reactive protein levels was observed after the match among junior soccer players. Similarly, no relevant changes in CRP were determined following the HIIT programme (Wiewelhove et al., 2015). It appears that CRP may not be a useful muscle damage marker for monitoring fatigue and recovery immediately following a soccer match in U-21 players. However, in their study, Kostrzewa-Nowak et al. (2015) stated that CRP levels could be a valuable tool to assess the metabolic response to aerobic exercise. Because the post-match inflammatory response of CRP levels has a 24-hour peak (Ispirlidis et al., 2008), this time-course could be considered as a valuable tool for assessing fatigue in soccer players. However, other explanations of the fatigue that occurs after the intense exercise periods in soccer should be sought.

During matches, some players will lose considerable quantities of electrolytes and may need to replace these during the match (Shirreffs, Sawka, \& Stone, 2006). Moreover, it has been suggested that the development of fatigue during high-intensity exercise is related to an accumulation of potassium in the muscle interstitium (Bangsbo, Madsen, Kiens, \& Richter; Sejersted \& Sjøgaard, 2000). This statement was supported by the observation of muscle interstitial potassium concentrations higher than $11 \mathrm{mmol} / \mathrm{l}$ during exhaustive exercise 
(Nielsen et al., 2004). The aforementioned values are high enough to depolarize the muscle membrane potential and reduce force development markedly (Cairns \& Dulhunty, 1995). Takarada (2003) found that plasma $\mathrm{K}^{+}$concentrations had significantly increased after the match, whereas plasma $\mathrm{Na}^{+}$concentration gradually decreased. Interestingly, we demonstrated reduced levels of plasma $\left[\mathrm{K}^{+}\right]$after a soccer match. However, the plasma $\left[\mathrm{Na}^{+}\right]$concentration was unchanged after an official soccer match in U-21 players, which is in line with Takarada (2003). Fraser et al. (2002) observed reduced maximal activity of the $\mathrm{Na}^{+} / \mathrm{K}^{+}$pump following different types of exercise. While these plasma values do not provide a clear picture of the concentrations around the contracting muscle fibres in soccer (Bangsbo, Mohr, \& Krustrup, 2006), further research is needed to reveal what may cause fatigue during a soccer game.

This study approached the analysis of muscle damage markers before and immediately after the match. The strength of our study lies in the fact that the results come from an official soccer match played by U-21 professional players. We can say that most selected markers of muscle damage were influenced by a soccer match. However, the results of this study, along with those of other numerous studies are inconsistent because of the influence of type, duration and intensity of exercise. Moreover, some markers show great variability among individuals. Therefore, more studies like this are needed to reveal which markers are essential for designing the proper training programme and how to prevent injuries and overtraining in professional soccer players.

\section{RE F E R E N C ES}

Andersson, H., Ekblom, B., \& Krustrup, P. (2008). Elite football on artificial turf versus natural grass: Movement patterns, technical standards, and player impressions. Journal of Sports Sciences, 26(2), 113-122.

Ascensão, A., Rebelo, A., Oliveira, E., Marques, F., Pereira, L., \& Magalhães, J. (2008). Biochemical impact of a soccer match-analysis of oxidative stress and muscle damage markers throughout recovery. Clinical Biochemistry, 41(10), 841-851.

Bangsbo, J., Madsen, K., Kiens, B., \& Richter, E. (1996). Effect of muscle acidity on muscle metabolism and fatigue during intense exercise in man. The Journal of physiology, 495(2), 587-596.

Bangsbo, J., Mohr, M., \& Krustrup, P. (2006). Physical and metabolic demands of training and match-play in the elite football player. Journal of sports sciences, 24(07), 665-674.

Brancaccio, P., Lippi, G., \& Maffulli, N. (2010). Biochemical markers of muscular damage. Clinical Chemistry and Laboratory Medicine, 48(6), 757-767.

Burger-Mendonca, M., Bielavsky, M., \& Barbosa, F. (2008). Liver overload in Brazilian triathletes after half-ironman competition is related muscle fatigue. Annals of Hepatology, 7(3), 245-248.

Byrne, C., \& Eston, R. (2002). Maximal-intensity isometric and dynamic exercise performance after eccentric muscle actions. Journal of Sports Sciences, 20(12), 951-959.

Cairns, S. P., \& Dulhunty, A. F. (1995). High-frequency fatigue in rat skeletal muscle: role of extracellular ion concentrations. Muscle and Nerve, 18(8), 890-898.

Cooper, C., Vollaard, N. B., Choueiri, T., \& Wilson, M. (2002). Exercise, free radicals and oxidative stress. Biochemical Society Transactions, 30(2), 280-285.

Davies, R. C., Rowlands, A. V., \& Eston, R. G. (2009). Effect of exercise-induced muscle damage on ventilatory and perceived exertion responses to moderate and severe intensity cycle exercise. European Journal of Applied Physiology, 107(1), 11-19.

Fatouros, I. G., Chatzinikolaou, A., Douroudos, I. I., Nikolaidis, M. G., Kyparos, A., Margonis, K., . . Katrabasas, I. (2010). Time-course of changes in oxidative stress and antioxidant status responses following a soccer game. The Journal of Strength \& Conditioning Research, 24(12), 3278-3286.

Finaud, J., Lac, G., \& Filaire, E. (2006). Oxidative stress. Sports Medicine, 36(4), 327-358.

Fraser, S. F., Li, J. L., Carey, M. F., Wang, X. N., Sangkabutra, T., Sostaric, S., . . McKenna, M. J. (2002). Fatigue depresses maximal in vitro skeletal muscle $\mathrm{Na}+-\mathrm{K}+$-ATPase activity in untrained and trained individuals. Journal of Applied Physiology, 93(5), 1650-1659.

Goldfarb, A. H. (1999). Nutritional antioxidants as therapeutic and preventive modalities in exercise-induced muscle damage. Canadian Journal of Applied Physiology, 24(3), 249-266.

Goldfarb, A. H., Garten, R. S., Cho, C., Chee, P., \& Chambers, L. A. (2011). Effects of a fruit/berry/vegetable supplement on muscle function and oxidative stress. Med Sci Sports Exerc, 43(3), 501-508.

Gregson, W., Drust, B., Atkinson, G., \& Salvo, V. (2010). Match-to-match variability of high-speed activities in premier league soccer. International Journal of Sports Medicine, 31(4), 237-242.

Halson, S. L. (2014). Monitoring training load to understand fatigue in athletes. Sports Medicine, 44(2), 139147.

Hammouda, O., Chaouachi, A., Ferchichi, S., Kallel, C., \& Souissi, N. (2012). Effect of short-term maximal exercise on biochemical markers of muscle damage, total antioxidant status, and homocysteine levels in football players. Asian Journal of Sports Medicine, 3(4), 239.

Heisterberg, M. F., Fahrenkrug, J., Krustrup, P., Storskov, A., Kjær, M., \& Andersen, J. L. (2013). Extensive monitoring through multiple blood samples in professional soccer players. The Journal of Strength \& Conditioning Research, 27(5), 1260-1271.

Hopkins, W., Marshall, S., Batterham, A., \& Hanin, J. (2009). Progressive statistics for studies in sports medicine and exercise science. Medicine+ Science in Sports+ Exercise, 41(1), 3.

Ispirlidis, I., Fatouros, I. G., Jamurtas, A. Z., Nikolaidis, M. G., Michailidis, I., Douroudos, I., . . Katrabasas, 
I. (2008). Time-course of changes in inflammatory and performance responses following a soccer game. Clinical Journal of Sport Medicine, 18(5), 423-431.

Kostrzewa-Nowak, D., Nowak, R., Chamera, T., Buryta, R., Moska, W., \& Cieszczyk, P. (2015). Post-Effort Chances in C-Reactive Protein Level Among Soccer Players at the End of the Training Season. The Journal of Strength \& Conditioning Research, 29(5), 1399-1405.

Lazarim, F. L., Antunes-Neto, J. M., da Silva, F. O., Nunes, L. A., Bassini-Cameron, A., Cameron, L.-C., . . . de Macedo, D. V. (2009). The upper values of plasma creatine kinase of professional soccer players during the Brazilian National Championship. Journal of Science and Medicine in Sport, 12(1), 85-90.

MacIntosh, B. R., \& Rassier, D. E. (2002). What is fatigue? Canadian Journal of Applied Physiology, 27(1), 42-55.

Magalhães, J., Rebelo, A., Oliveira, E., Silva, J. R., Marques, F., \& Ascensão, A. (2010). Impact of Loughborough Intermittent Shuttle Test versus soccer match on physiological, biochemical and neuromuscular parameters. European Journal of Applied Physiology, 108(1), 39-48.

Meister, S., Faude, O., Ammann, T., Schnittker, R., \& Meyer, T. (2013). Indicators for high physical strain and overload in elite football players. Scandinavian Journal of Medicine and Science in Sports, 23(2), 156-163.

Mougios, V. (2007). Reference intervals for serum creatine kinase in athletes. British journal of sports medicine, 41(10), 674-678.

Muñoz, A., \& Costa, M. (2013). Nutritionally mediated oxidative stress and inflammation. Oxidative Medicine and Cellular Longevity, 2013.

Neubauer, O., König, D., \& Wagner, K.-H. (2008). Recovery after an Ironman triathlon: sustained inflammatory responses and muscular stress. European Journal of Applied Physiology, 104(3), 417-426.

Nielsen, J. J., Mohr, M., Klarskov, C., Kristensen, M., Krustrup, P., Juel, C., \& Bangsbo, J. (2004). Effects of high-intensity intermittent training on potassium kinetics and performance in human skeletal muscle. The Journal of physiology, 554(3), 857-870.

Nybo, L., Girard, O., Mohr, M., Knez, W., Voss, S., \& Racinais, S. (2013). Markers of muscle damage and performance recovery after exercise in the heat. Med Sci Sports Exerc, 45(5), 860-868.

Reilly, T. (1997). Energetics of high-intensity exercise (soccer) with particular reference to fatigue. Journal of Sports Sciences, 15(3), 257-263.

Sejersted, O. M., \& Sjøgaard, G. (2000). Dynamics and consequences of potassium shifts in skeletal muscle and heart during exercise. Physiological Reviews, 80(4), 1411-1481.

Shanely, R., Nieman, D., Henson, D., Jin, F., Knab, A., \& Sha, W. (2013). Inflammation and oxidative stress are lower in physically fit and active adults. Scandinavian Journal of Medicine and Science in Sports, 23(2), 215-223.

Shirreffs, S. M., Sawka, M. N., \& Stone, M. (2006). Water and electrolyte needs for football training and match-play. Journal of Sports Sciences, 24(07), 699-707.

Silva, J. R., Ascensao, A., Marques, F., Seabra, A., Rebelo, A., \& Magalhaes, J. (2013). Neuromuscular function, hormonal and redox status and muscle damage of professional soccer players after a high-level competitive match. European Journal of Applied Physiology, 113(9), 2193-2201. doi: 10.1007/s00421-013-2633-8

Speranza, L., Grilli, A., Patruno, A., Franceschelli, S., Felzani, G., Pesce, M., . . . Felaco, M. (2007). Plasmatic markers of muscular stress in isokinetic exercise. Journal of Biological Regulators and Homeostatic Agents, $21(1 / 2), 23$

Stoner, L., Lucero, A. A., Palmer, B. R., Jones, L. M., Young, J. M., \& Faulkner, J. (2013). Inflammatory biomarkers for predicting cardiovascular disease. Clinical Biochemistry, 46(15), 1353-1371.

Suzuki, K., Totsuka, M., Nakaji, S., Yamada, M., Kudoh, S., Liu, Q., . . Sato, K. (1999). Endurance exercise causes interaction among stress hormones, cytokines, neutrophil dynamics, and muscle damage. Journal of Applied Physiology, 87(4), 1360-1367.

Takahashi, I., Umeda, T., Mashiko, T., Chinda, D., Oyama, T., Sugawara, K., \& Nakaji, S. (2007). Effects of rugby sevens matches on human neutrophil-related non-specific immunity. British journal of sports medicine, 41(1), 13-18.

Takarada, Y. (2003). Evaluation of muscle damage after a rugby match with special reference to tackle plays. British journal of sports medicine, 37(5), 416-419.

Taylor, J. L., Allen, G. M., Butler, J. E., \& Gandevia, S. (2000). Supraspinal fatigue during intermittent maximal voluntary contractions of the human elbow flexors. Journal of Applied Physiology, 89(1), 305-313.

Thompson, D., Williams, C., Garcia-Roves, P., McGregor, S., McArdle, F., \& Jackson, M. (2003). Post-exercise vitamin C supplementation and recovery from demanding exercise. European Journal of Applied Physiol ogy, 89(3-4), 393-400.

Urhausen, A., \& Kindermann, W. (2002). Diagnosis of overtraining. Sports Medicine, 32(2), 95-102.

Vollaard, N. B., Shearman, J. P., \& Cooper, C. E. (2005). Exercise-induced oxidative stress. Sports Medicine, 35(12), 1045-1062.

Wiewelhove, T., Raeder, C., Meyer, T., Kellmann, M., Pfeiffer, M., \& Ferrauti, A. (2015). Markers for Routine Assessment of Fatigue and Recovery in Male and Female Team Sport Athletes during High-Intensity Interval Training. PloS One, 10(10), e0139801. 